\title{
LA OBRA HISTORIOGRÁFICA DE JORGE BASADRE, UNA LECTURA PERUANISTA DE NUESTRA HISTORIA ${ }^{1}$
}

\author{
Eusebio Quiroz Paz Soldán
}

\section{RESUMEN}

En la vasta producción intelectual del doctor Jorge Basadre Grohmann, puede señalarse con nitidez, dos notas características: primera, que se trata de una obra historiográfica, y, segundo, que esta obra es peruanista. Ambos aspectos resultan inseparables en un análisis del legado que nos entregó con su vida este ilustre historiador. Los dos elementos de caracterización de su obra se inscriben en la vida misma de este autor, formando un todo integral en el que la práctica profesional, la docencia universitaria, el amor por el Perú y el ejercicio de valores éticos y morales, tienen un mismo correlato. Vida y obra tienen así en Basadre, una coherencia que les concede sustento sólido y que sirve como modelo de consecuencia para la juventud peruana.

Nos proponemos mostrar el peruanismo de esta obra historiográfica y encontrar las bases del mismo, más allá de consideraciones subjetivas o patrióticas. Haremos un esfuerzo por penetrar en el pensamiento historiografía de Basadre, buscando su idea del Perú. No olvidemos que una de las direcciones de su trabajo fue el elaborar una Teoría del Perú, vale decir una explicación científica válida, acerca de cómo se formó el Perú, cómo se ha desarrollado y qué podríamos hacer para ofrecerle un mejor "destino histórico", un futuro donde pueda desarrollarse la "promesa de la vida peruana", es decir, las posibilidades y potencialidades a que está llamado el Perú.

\section{La "lectura" de la historia}

El pasado es recreado intelectualmente por el historiador, a través de una investigación que toma como base los documentos, huellas, testimonios o fuentes que nos lo revelan. El científico, utilizando el método crítico, obtiene información de las fuentes que selecciona y con la que crea una imagen orgánica, congruente y ordenada del pasado. En los resultados de la investigación hecha por el

* Historiador. Universidad Nacional San Agustin de Arequipa

'Publicado en: Alejandro Málaga Medina. Homenaje (1935-1995). Ed. Academia Peruana de Historia Eclesiástica. Arequipa. historiador, está explícita esta imagen histórica del pretérito, que implica también una manera de "ver" el pasado por el científico. Podemos encontrar en la presentación de la exposición histórica una determinada "lectura" del pasado. Entiéndase por "lectura" el punto de vista del historiador acerca de la realidad pretérita que ha investigado; pero no sólo se trata de un punto de vista, como suele entenderse comúnmente, sino de una toma de posición del historiador ante la materia histórica sobre la que trabaja. 
"Lectura" en éste sentido es más que el acto de leer, o sea "recorrer con la vista lo escrito o impreso para enterarse de ello"; más bien es interpretar un texto, dar a conocer, averiguar, penetrar una cosa oculta y oscura. Por extensión se usa un concepto más amplio de lectura, en tanto que discurso.

Discurso, en sentido amplio, es la "descripción formal de los conjuntos de palabras superiores a la frase", según Roland Barthes. La antigua retórica, afirma este autor, tenía como objeto específico el discurso, que ha pasado hoy al dominio de la lingüística de la semiología.

Habría, de este modo, una diferencia entre el discurso poético, el novelesco y el relato histórico. Este último es muy importante de reconocer, ya que muchos usan el término "relato" ó narración histórica como un género literario, sin advertir que la literatura, en sentido estricto, es obra de ficción e imaginación libre del autor, y que el llamado relato histórico tiene exigencias gnoseológicas, relacionadas con el método y con su contenido.

Un texto redactado por un historiador, a base de una síntesis, apoyado en un procedimiento científico, no es la copia ni repetición del contenido de las fuentes. Esa práctica suele llamarse "documentolatría", ya que lleva al documento a la categoría de un texto sacro, que no lo es.

El historiador elabora el resultado de su investigación, y pone en ello su visión del mundo y de la vida, agrega un punto de vista -la lectura del pasado- que caracteriza su discurso y lo hace reconocible. Es cierto también, que la vigencia de los resultados de la investigación es variable. Afirma José G. Nugent que los historiadores poseen una autoridad cultural en el Perú para dictaminar sobre las cosas a partir de lo que fueron; la historia del Perú no es pensada, agrega, en función de los peruanos, sino de las palabras de los historiadores (Nugent, 1992: 100-101).

La autoridad del científico social que investiga el pasado, no procede del texto aprobado por el gobierno, sino de la ética del compromiso con la verdad-del historiador, y de someter los resultados de su pesquisa al principio científico de verificación y de revisión del proceso de investigación, cuyos resultados expone el científico. Es obvio que no todos aprueban este análisis de consistencia.

El discurso historiográfico, en opinión de Nugent, es "una propuesta de orientación para los contemporáneos" (Nugent, 1992: 102]. Este es el se ni ido de lo que suele llamarse "historia oficial", si es que aceptamos que el historiador elabora exprofeso un discurso legitimador ó, en el peor de los casos, una versión que encubre hechos de los que no se quiere hablar o que se pretende evitar que los conozca directamente la colectividad. Este sentido de "historia oficial", proveniente desde el poder, se aplica a la historiografía que se expone con autorización o beneplácito por los gobernantes de uno, como sucedió en la Alemania nazi ó en la época estaliniana de la Unión Soviética.

Cuando el rigor y la solidez del discurso historiográfico están bien estabilizados, el historiador crea una teoría que nos aproxima a la comprensión del pasado y nos facilita la explicación del presente. No dejemos de lado la aseveración que dice "la historia es la ciencia de los porqué". Respondiendo preguntas, planteando significados, analizando perspectivas, aparece ante nosotros la "lectura" del pasado, que está implícita en el discurso 
historiográfico.

En la vasta obra historiográfica del doctor Jorge Basadre, podemos hallar una orientación, una lectura del pasado y una teoría del Perú, ya que el objetivo más importante de la investigación histórica hecha por este ilustre historiador, es el conocimiento de la historia del Perú en toda su amplitud.

Planteamos en este trabajo que existe una lectura peruanista en la obra historiográfica de Basadre, y que ella, junto con una teoría del Perú, puede encontrarse como referencia permanente en los libros y textos publicados por este autor. Como puede colegirse de los títulos de las obras de Basadre, estas llevan explícita una lectura peruanista ele la historia del Perú, salvando la redundancia. "Perú. Problema y Posibilidad", "La promesa de la vida peruana", "Meditaciones sobre el destino histórico del Perú", "La idea del Perú en la generación independiente", "Con el pueblo y por la patria"; es fácil encontrar que la alusión frecuente al Perú como promesa, como esperanza, como posibilidad, no es un recurso literario, sino un desarrollo de sus ideas sobre la historia.

En consecuencia, apreciamos que la lectura que hace Basadre de la historia del Perú está orientada por un aparato teórico que ha sido estudiado por: Francisco Miro Quesada, Helen Delpar, Franklin Pease, María Emilia Mannarelli, etc. , y que revela la coherencia intelectual de un académico serio, cuya obra es fruto de largos años de investigación histórica y de paciente elaboración teórica. Así, aparece también una concepción, una teoría y unas ideas históricas en Basadre, que dan fuerza a su lectura peruanista de nuestra historia.

Posteriormente será citado como reflexiones

\section{Las ideas de Basadre sobre la historia}

Jorge Basadre afirmó que la esencia de la historia no es otra que la vida humana: $A$ partir de este aserto podemos aproximarnos a su concepción de la historia y del trabajo del historiador. La historia busca "... el señalamiento de una inteligencia y un juicio sobre el drama humano, drama que empezó mucho antes de que naciéramos y que seguirá después que nos hayamos ido" (Basadre, 1968: XLIII, de esta manera define el interés de la pregunta histórica.

La historia, según Basadre, es una ciencia por su apego a la verdad posible y arte por el aura de belleza que acompaña a toda evocación y afirmación de la vida. La historia como ciencia descubre las relaciones entre los hechos. transformándolos en parte de un todo con "sentido", en materia inteligible; por lo tanto, Basadre considera a la historia como una disciplina científica con base teórica, cuyos resultados no son nunca definitivos, sino que están abiertos a nuevos aportes, además porque aplica una metodología que consiste "en elaborar una hipótesis que explica porque las cosas fueron como fueron y en consecuencia comprender porqué el presente es como es" (Miro Quesada, 1978: 197). Sostiene Basadre que, "partiendo de lo empírico, el método de las ciencias culturales utiliza pues una dialéctica para comprender, explicar o interpretar; va del substrato del objeto hacia su sentido y luego viceversa hasta que quepa considerar lograda la comprensión. La naturaleza se explica, la vida del espíritu se comprende" (Basadre, 1967: 10)-según Francisco Miro Quesada, la concepción histórica de Basadre.es hipotética -comprensiva, de carácter probabilística, ya que en sus "Reflexiones sobre la historiografía" ${ }^{2}$ nos dice que no hay 
verdadera historia sin hipótesis de trabajo.Entonces, siguiendo a Basadre decimos que la historia "es conocimiento del hombre por el hombre, aprehensión de la vida en sus múltiples formas, dentro de los límites de lo relativo y de lo contingente" (Basadre, 1968: XXXVIII).

Podemos establecer que desde su concepción de la historia, encontramos ya un elemento de utilidad en ésta, la de comprender dos aspectos: la conducta humana y como las relaciones sociales afectan ésta; así el pasado no es importante en sí mismo, sino en la medida que repercute o influencia a las generaciones siguientes". De ello se deduce que todo es "Insumable" para el historiador.

El primer acercamiento que uno tiene a la historia, es para lo que Basadre llamó: "el goce y la hazaña del saber", esto implica, según él, revivir, evocar, comprender, juzgar ó interpretar, obteniéndose todo eso a través de un duro "esfuerzo, severa técnica y metódica labor. Rigor en el manejo de las fuentes, serenidad para tratar de dar a cada uno lo suyo" (Basadre, 196S).

El conocimiento del pasado nos permite tomar conciencia de nuestro presente, teniendo una "visión más rica y más profunda" de este. Podemos decir que Basadre resume la importancia de la historia en tres puntos: porque nos suministra un sentido de comprensión para la cultura, el país, la localidad; porque nos puede infundir un concepto de continuidad y porque puede hacernos entender mejor el presente. Advierte además, que la historia no profetiza el futuro.

Pero la historia no existe sin el historiador, es el mundo histórico de éste que, intensamente sacudido por la información de las fuentes, va recreando intelectualmente, un cuadro orgánico del pasado, conjugando así el esquema científico ele la investigación con los datos que reúne de las fuentes. Es por él que la historia esta vinculada a la cultura de cada época.

Cuando Basadre plantea una historia libre y perspectivista (Basadre, 1971:1056), no sólo quiere decir que busca la elaboración de una historia que no obedezca a intereses ele grupo y que considere diversas perspectivas, sino también que el historiador sea libre y capaz de superar lo sectario, lo apriorístico, lo primario; respetando la integridad y la independencia del pasado, pudiendo de esta manera aportar veraces y útiles observaciones sobre éste. Nos dice que una interpretación orgánica del pasado debe ser pluralista, ya que no hay sector de la actividad humana que no pueda convertirse en tema para el historiador. Así la "grandeza y la servidumbre de la historia consiste en que el historiador crea su propio objeto" (Basadre, 1968: XXXVII).

Propone además, que la tarea del historiador consiste primordial mente, en "una aprehensión del tema por él tratado, mediante la compulsa de datos y el empleo de la intuición y de la comprensión, a la vez que en una aventura espiritual" (Basadre, 1968: XXXVIIIJ. Agrega que la historia es ciencia por la crítica, y el historiador debe tener espíritu crítico en su búsqueda de la verdad sobre el pasado. No se debe poner la historia al servicio del interés personal; pero advierte también, que la objetividad no es tratar de ser imparcial, sino de "dialogar con el pasado en tono sereno, para que la débil voz de este no sea acallada por el tumulto subjetivo" (Basadre, 1968: XL1V); debe resaltar en el historiador además, la integridad de conciencia, autenticidad de 
vocación, fidelidad hacia ella y sinceridad con uno mismo y con el pasado.

Basadre es historiador por vocación, como afirmó Percy Cayo, y al leerlo descubrimos que tiene un profundo dominio del campo profesional y académico de la investigación histórica, también porque comprendió a cabalidad la utilidad de la difusión del conocimiento histórico, para la sociedad contemporánea; y la llevó a cabo sin anteponer sus pretensiones personales, pero sí el amor que profesaba al país, al ser humano, a la vida; "la historia es una ciencia de la vida. Y es la vida lo que pretende tomar como tema (Basadre, 1968: XI.II), esta es, según César Pacheco Vélez, la convicción de Basadre.

En la obra de Jorge Basadre podemos encontrar una "lúcida conciencia filosófica" que tiene un carácter epistemológico, y que, según Francisco Miro Quesada, esto "produce una concepción unitaria en toda su obra historiográfica, que permite la presentación sistemática de la realidad histórica, ya que analiza desde un principio sobre que es historia y sobre las posibilidades del conocimiento histórico" (Miro Quesada, 1978: 191). Siguiendo al mismo autor podemos repetir, que en la obra de Basadre encontramos los siguientes planteamientos filosóficos: a] la historia (como historiografía) es una teoría científica, b] es posible alcanzar la verdad histórica, es posible llegar a conocimientos históricos objetivos, c) el conocimiento histórico, aunque objetivo, es probable; los conceptos de azar y de probabilidad son fundamentales para su constitución, d) el contenido de la historia es la conducta humana intersubjetiva y e) aunque no puede elaborarse una filosofía de la historia de tipo especulativo, es lícito meditar sobre el sentido de la historia, es decir, dentro de ciertos límites impuestos por la exigencia de verificación empírica de toda ciencia de los real, puede y debe haber una filosofía de la historia.

Esta concepción teórica, además del uso directo de las fuentes para determinar el contenido de los temas tratados, el descubrimiento de nuevos hechos históricos analizados en detalle, y minuciosidad descriptiva al momento de la síntesis, es la que caracteriza la obra historiográfica de Jorge Basadre, cuyo referente es el pasado del Perú en tanto que realidad histórica pretérita.

El acceso a las fuentes, nos muestra en Basadre una actitud más amplia respecto a ellas. En sus "Reflexiones..." afirma, que es válido utilizar "todo lo que pueda ser interpretado como índice revelador de cualquier aspecto de la presencia, la actividad, los sentimientos o la mentalidad de los hombres de ayer", considerando que "toda fuente de información que permita conocer al historiador alguna cosa sobre el espíritu del pasado es un documento" (Basadre, 1968: XXXVII); en este sentido sigue el pensamiento de H.I. Marrou, quien ha aportado un concepto amplio y esencial de fuente histórica, llamándola "documento" (Marrou, 1968: 59). A esta apreciación sobre las fuentes se agrega una idea fundamental, acerca de la incapacidad de reunir con todas sobre un hecho determinado, por eso consideró que la obra histórica es, por fuerza, limitada y superable, entre otras razones por el descubrimiento de nuevos documentos.

El conocimiento posible de la verdad del pasado, del que escribía Basadre. significaba además, la plasmación de una historiografía, tiene, según nuestro autor, un tremendo poder destructivo de los dogmas. Además nos dice que cada época necesita, y debe de elaborar, su propia 
historiografía.

El desarrollo de la historiografía se debió a intereses distintos, en sus inicios predominó la historia política, diplomática y militar; posteriormente se comenzó a estudiar la historia de la cultura, de la civilización; Basadre afirma que "aparte de lo acontecimientos, se buscó entonces las estructuras ocultas yacentes debajo del oleaje fácilmente visible de las acciones, los gestos y las palabras (Basadre, 1965: 4).

En la obra de Basadre no sólo encontramos esa parte teórico, metodológica y epistemológica sobre la concepción de la historia, filosofía de la historia, la posición científica sobre ésta y la función social de la historia y del historiador; también se presenta y se muestra "el oficio del historiador", su tarea como compromiso insobornable con la ciencia y con la verdad, donde la primera resulta profesional, casi técnico, y la segunda es ética y moral, aquí se revela a Basadre como ejemplo por ésa valía espiritual superior.

Debemos resaltar que en la obra de Jorge Basadre encontramos consecuencia entre su concepción teórica sobre la historia y el resultado de la investigación realizada. Según Miro Quesada, Basadre "no solo ha tenido una concepción nueva de la historia, verdaderamente pionera, sino que ha tenido la energía y el talento suficientes para realizarla. $Y$ ha tenido, además, la pureza de intención y el coraje moral que le exigía la realización de una obra tan extraordinaria" (Miro Quesada, 1978:206].

Por otro lado, Pablo Macera expresó el 22 de setiembre de 1994 que: "Basadre no creía que la historia pudiera ser reducida a una investigación de la verdad, si no que debía verse además como un modo ele sacar a los hombres de sí mismos para colocarlos en una consiente relación con el mundo, de tal modo que pudieran considerarse como actores responsables ele un proceso que comenzó antes que ellos nacieran y continuara después ele su muerte. Pero un proceso que en definitiva puede sufrir rectificaciones respecto al pasado y con relación al futuro". Agrega además, César Pacheco Vele/, que: en Basadre encontramos a un hombre ajeno a la vanidad de la "obra acabada o definitiva," todo lo contrario, existe en él un "peregrino quien apasionadamente trabaja entre las fuentes en la búsqueda serena de la conciencia de una identidad para su patria".

\section{Jorge Basadre: historiador peruanista}

\subsection{Los peruanistas}

En el Primer Encuentro Internacional de Peruanistas, llevado a cabo en 1996, se afirmó que "el Perú la compleja realidad peruana en sus múltiples aspectossuscitó, ha suscitado siempre, el vivo interés de estudiosos nacionales y extranjeros que desde antiguo, y luego en una ininterrumpida y cada vez más rica secuencia han venido desarrollando un conocimiento del Perú en los campos de prácticamente todas las ciencias humanas, sociales y naturales. A estos científicos e intelectuales, que comprometidos en esta empresa han hecho de lo peruano el tema principal la menudo el únicol de sus preocupaciones. se les llama tradicionalmente peruanistas" (Universidad de Lima, 1996: 11).

\subsection{Hipótesis sobre el peruanismo de Jorge Basadre}

Basadre defendió una concepción científica de la historiografía, en la que la objetividad 
era posible y en la que el historiador debía evitar poner sus pasiones e intereses en la síntesis que resultaba de su investigación. No sólo adoptó un punto de vista, estrictamente profesional ante su tarea, sino que hizo de ella un compromiso con la verdad sobre el pasado.

No son numerosos los historiadores que están premunidos de una sólida base teórica acerca de los fundamentos de su disciplina, de tal modo que sean conscientes de sus limitaciones y de las exigencias de su labor. Entre ellos, Basadre brilla por su conocimiento y porque explícita su concepción "sinfónica" de la historia, como lo expresa en las páginas iniciales de la Historia de República del Perú.

Para efectos del tema de este trabajo, surge de la obra historiográfica del autor que seleccionamos, una "lectura" de nuestra historia; una lectura peruanista. Debemos entender por lectura peruanista, una visión que proyecta una idea del Perú, del pasado al presente, una propuesta de compromiso "con el pueblo y por la patria" ya que planteó con claridad que para su concepto, ser peruano era tener obligaciones y deberes que, lógicamente, deben realizarse en el presente y en el futuro. No es pues un discurso para lectores desaprensivos el que sale de las páginas de la obra de Basadre, es, lo repetimos, una lectura peruanista, optimista, constructiva, esperanzada hacia adelante.

\subsubsection{La infancia en Tacna y la "patria ausente"}

Pero la formación peruanista de Basadre, la podemos encontrar desde tiempo antes. Así en un artículo de Percy Cayo, titulado: "Historiador por vocación", plantea que tanto el lugar como la época en que nació
Jorge Basadre, son circunstancias especiales, para reflexionar sobre su amor y compromiso con el Perú.

Jorge Basadre no puede ser considerado, solamente peruanista, en el sentido al que alude el concepto citado ut supra, sino en el más amplio de la lectura de la historia peruana desde una perspectiva esperanzadora que afirma valores y conductas colectivas percibidas en la investigación histórica. Así, cuando escribe acerca de la "promesa de la vida peruana, alude, sin duda, a una visión constructiva y optimista de la historia, que obviamente guarda estrecha relación con sus ideas acerca de la forma como el historiador reconstruye el pasado, científicamente. Es lo que la pesquisa de los hechos humanos y sociales pretéritos, le revela acerca del Perú y su desarrollo histórico. Por ello resulta válido sostener que en la obra de Basadre se encuentra una teoría del Perú en tanto que comprensión y explicación de la conformación histórica de la realidad peruana.

El peruanismo de Basadre, sustentado en el conocimiento sobre el pasado, es afirmativo de la expectativa de construir una sociedad justa, fraterna y solidaria, que nuestro autor encuentra en el proceso histórico de la vida peruana, donde recoge una experiencia, un ideal, una posibilidad y una promesa.

Postulamos aquí una primera hipótesis acerca del origen del peruanismo de Basadre: su sentimiento infantil, de la "patria ausente" durante los años de la ocupación chilena de Tacna y que recuerda con vivida emoción en "Infancia en Tacna" y luego desarrollada en su libro "La vida y la Historia", donde registra el recuerdo imborrable de la canción que su madre, la señora Olga Grohmann de Basadre, 
cantaba en los primeros años del Niño. A lo anterior se agrega el recuerdo de la escuela de primeras letras, donde inició sus estudios, dirigida por la maestra Carlota Pinto de Gamallo (Basadre, 1975). Basadre afirma que descubrió en su infancia, sus "raíces en la tierra", se refiere a Tacna, y eso era el Perú ocupado por fuerzas militares y autoridades políticas extranjeras, a comienzos del siglo $X X$; no nos cabe duda que el amor por el Perú que mostró en toda su vida y obra, se nutrió fuertemente de esa imborrable experiencia infantil, que volvería a adquirir dimensiones de nostalgia y ausencia, cuando con su familia se traslada a vivir a Lima en 1912 . dejando atrás el mundo feliz de la infancia, así nos dice que "sentirse enraizado en la tierra propia es, acaso, el mejor privilegio que un niño puede alcanzar. Si el terruño posee belleza y personalidad, le ha de estampar, sin que de ello se de cuenta, ese sentido de compenetración con el mundo físico circundante que es el más humilde y el más feliz de todos los dones otorgados por la vida" (Basadre, 197'»: ">)

Encontró desde entonces gusto por la lectura, inculcado por su madre, además la familia de Basadre estaba relacionada con la historia de Tacna; cabe mencionar que dos prinos hermanos de su padre, lucharon y murieron en la Batalla de Arica (Cayo, 2001).

Percy Cayo plantea que la vocación de historiador y el amor a la patria, se desarrollaron desde la infancia, el ejemplo familiar fue un factor determinante para su peruanismo. Posteriormente cuando Basadre deja Tacna, para trasladarse a Lima, el sentimiento patriótico, se desarrollo más.

Por otra parte, en las "Conversaciones", que sostuvo con Pablo Macera, Basadre nos dice que sus investigaciones nacieron por una necesidad desde el fondo de su ser y que esta se convirtió en parte de su existencia; podemos decir que esa necesidad era la de explicar la compleja realidad peruana a partir de la comprensión del su pasado, pero esta necesidad no fue satisfecha completamente en toda su obra.

\subsubsection{En Lima: la Generación del Novecientos}

Para comprender mejor el peruanismo de Basadre, debemos mencionar la generación a la que perteneció y la anterior, ya que en ellas puede encontrase un segundo elemento que configura su peruanismo. César Pacheco plantea, que "la historia no es sólo el pasado, lo es en a medida en que pervive y se proyecta en nosotros y en quienes han de sucedemos" (Pacheco, 1964: 2); agrega además que las grandes figuras de nuestra historiografía son producto de una visión de conjunto e integral de todo nuestro pasado histórico, "sin anatemas ni exclusivismos".

A principios del siglo $X X$ se presenta en el escenario político cultural del Perú una nueva generación, que se le llamó la "Generación del novecientos" o "Arielista", la aparición de esta fue producto de la dramática derrota en la Guerra del Pacífico y de las luchas internas posteriores al conflicto. Esta llevo consigo el anhelo de "redescubrirse y "encontrase". Grandes personajes, en distintos campos de la cultura, forman parte de ella, entre los que influenciaron de cierta forma la obra de Basadre, José de la Riva Agüero Víctor Andrés Belaúnde, Francisco García Calderón, entre otros; las ideas de este ultimo, fueron difundidas por Basadre en su obra "La iniciación de la República", ya que, "Le Perou Contemporain" de García 
Calderón, recién se difundió en español en la segunda mitad del siglo XX.

Pablo Macera plantea que la lección que de este grupo se desprende para las generaciones presentes y venideras, era consolidar la peruanidad, apagar odios y diferencias para crear el gran Perú mestizo y cristiano (Macera, 1968); Belaúnde señaló que esta generación tuvo ansias de objetivismo, realismo e inmediatismo.

A la generación del novecientos debe reconocérsele el haber tomado del Perú su historia y su realidad como objeto de estudio, al que se aplicó, el aparato teórico y analítico de que disponían entonces. Ese fue el comienzo del camino, de los, así denominados, peruanistas.

\subsubsection{En San Marcos: la Generación de la Reforma Universitaria y del Conversatorio}

A principios de la década del '20 surge una nueva generación, la que participó de la Reforma Universitaria. Los acontecimientos que influyeron sobre el carácter de esta generación según Mana Emma Mannarelli, son:1] EI desmantelamiento del dominio político oligárquico por obra de Leguía 2) Las pugnas de los sectores populares y clases medias por ubicarse en un lugar autónomo en la política, 3) La mesocratización de la Universidad y la lucha por su reforma, y 4] Las influencias de las revoluciones mexicana y rusa, además de la difusión de las ideas democráticas y revolucionarias por movimientos sociales (Mannarelli, 1982).

David Sobrevilla la denomina como la generación "de la emergencia de los planteamientos socialistas", ya que por ese entonces existía un fuerte debate, político ideológico, entre José Carlos Mariátegui y Haya de la Torre.

En 1919 Basadre ingresa a la Universidad Nacional de San Marcos, desde un principio participó destacadamente en las actividades académicas de la institución. Sobre el Conversatorio, Basadre nos dice que "al aproximarse la fecha en que debía conmemorarse el centenario de la Independencia, un grupo de jóvenes "reformistas" bajo el comando de Porras, decidió organizar, el Conversatorio Universitario para presentar, a través de una serie de conferencias que podían ser seguidas por debates públicos, sus puntos de vista acerca del ambiente que presidió y que rodeó a la Emancipación", "la orientación de las monografías que se presentaron en el Conversatorio Universitario no fue reaccionaria, sino un liberalismo crítico e independiente las definió". Basadre no participó con una monografía ni exposición, en el Conversatorio, pero Raúl Porras lo invitó para estar presente en los debates, Basadre nos dice que a sus dieciséis años aún no había realizado estudios maduros de investigación histórica, salvo el discurso que pronuncio en el Colegio Guadalupe sobre Francisco Bolognesi, pero se comprometió en ese momento a dar un aporte en el futuro (Basadre, 1975: 147). José Gálvez hizo un comentario en la revista Mundial del 28 de julio de 1921, llamándolos "la Generación del Centenario". Por esta razón Basadre, aparece vinculado con la Generación del Centenario de la Independencia, y con el grupo del Conversatorio Universitario; lo que es más importante es que en este grupo humano, intelectual y académico, se puso en práctica, un redescubrimiento del Perú, desde la perspectiva de diferentes disciplinas. Nos parece que esta es otra de las fuentes de afirmación del peruanismo 
de Basadre, que se suma a su fuerte percepción del Perú desde la infancia.

Aunque la respuesta a los problemas del Perú, que presenta la Generación de la Reforma Universitaria, no fue homogénea, encontramos en esta, como en la anterior generación, la consolidación del prestigio social de la historia, como sostiene Pablo Macera (Macera, 1968). De hecho, aparecía la historiografía como un elemento fundamental, necesario, para una visión del Perú, en momentos en que la realidad nacional estaba convulsionada por una coyuntura política y social compleja, en la que sobresalía la acción del presidente Leguía, y su grupo, que ciertamente transformó el panorama social del Perú. Vista desde esta perspectiva, la historiografía adquiría una dimensión social muy importante, que fue captada, entre otros, por Basadre, que desarrolló intensamente la investigación histórica.

Según afirma nuestro autor, en "Perú. Problema y Posibilidad", su generación tuvo dos momentos, el primero tuvo un contorno político bajo, luego, gracias a la solidaridad entre los estudiantes y el proletariado, adquiere un carácter político más definido.

En 1923, cuando la lucha universitaria definió rumbos más políticos que académicos, Basadre tomó una actitud independiente, sin dejar de pensar en los problemas peruanos. Su primera preocupación fue la de aclarar el panorama político-doctrinario de los primero años de la República.

Aunque encontramos mayor tensión interna en la generación de la Reforma Universitaria, que en la del novecientos, esta tuvo una gran contribución, que, según Macera, la podemos resumir en los siguientes puntos: a) conciliaron la experiencia histórica peruana con el pensamiento político europeo contemporáneo (Haya-Mariátegui), b) reintrodujeron la preocupación económica en la historia, c) ajustaron el estudio del pasado peruano a las necesidades de explicar y resolver los problemas sociales del presente, d) asumieron la divulgación de los hallazgos historiográficos, soldando el vacío entre la investigación y la docencia, y e) reanalizaron críticamente, no soló los conocimientos históricos ya adquiridos, sino también las fuentes y los métodos que hasta entonces se utilizaron (Macera, 1968).

David Sobrevilla define de la siguiente manera la posición política de Basadre: "creía que el socialismo era la mejor opción, pero un socialismo que fuera nacionalista y que tuviera en cuenta los problemas multiétnicos del Perú. Este socialismo debía ser, además, democrático, recogiendo los mejores elementos de la tradición liberal" (Sobrevilla, 1992: XV). En todo caso, Basadre habló y escribió de un socialismo "con rostro humano", lo cual implica una crítica al llamado socialismo soviético, y a otros realizados violentamente. No puede afirmarse, de ninguna manera, que Basadre, como historiador siguiera las ideas del marxismo. Puede percibirse una maduración entre la concepción político-social de Basadre y sus ideas acerca de la historia como realidad pasada; en cuanto a la primera anheló que el Perú avanzara hacia una promesa de justicia, armonía y fraternidad, y en cuanto a la segunda pensó en una idea global, total, sin privilegiar ninguno de los sectores de la actividad social humana. Ambos aspectos aparecen entrelazados en el peruanismo, que examinamos en este trabajo. Dicho en otros términos, Basadre entrelazó la promesa de la vida peruana 
para el futuro, con una búsqueda de la afirmación de esa promesa en la experiencia histórica del pretérito peruano.

\subsubsection{Propuesta de un esquema comprensivo de la obra de Jorge Basadre}

La obra historiográfica de Basadre puede ser clasificada de acuerdo a diversos criterios temático o cronológicos. Dentro del primero podemos reconocer las investigaciones propiamente históricas y los temas teóricos- metodológicos.

Jorge Basadre, en "Conversaciones" con Pablo Macera, postula Una división de sus trabajos, la primera etapa en obras de juventud, que va desde 1919 hasta 1931. antes de su viaje a Estados Unidos y Europa, sobre esta etapa nos dice que "es un periodo de reunión de búsquedas, informaciones y de compulsa de datos, así como también de formulación de esquemas dentro de un trabajo espontáneo" (Macera, 1979: 47). A su regreso al Perú en 1935 , comienza una nueva etapa, donde desarrolla el esquema de la Historia de la República del Perú, pero advierte que, influenciado por las obras de Monmsen y Herbert Fisher, elaboró una historia unilateral, una historia política. Esta etapa culmina en 1950 cuando participa en la elaboración de una historia de la humanidad auspiciada por la UNESCO, donde, en reuniones en Francia, conoce a los integrantes de la Escuela de los "Annales", aunque resalta que no está totalmente de acuerdo con su método histórico (Macera, 1979:41).

Podría deducirse que atendiendo a los planteamientos de Basadre en la "Conversaciones", puede establecerse tres

\footnotetext{
${ }^{3}$ En un estudio anterior titulado "El legado de Jorge Basadre", propusimos una división temática de su obra historiográfica, diferenciamos dos temas básicos: la historia del Perú y los temas teóricos metodológicos (Quiroz, 1988).
}

momentos o periodos en su obra: de 1919 a 1931, otra de 1935 a 1950 y un tercero ele 1950 en adelante. Tomando como base esta periodificación, otros investigadores de la obra de Basadre han postulado otras categorizaciones, así María Emma Mannarelli, a partir de los cambios en los procesos políticos culturales, plantea tres ciclos: el primero va desde 1919 hasta 1931, es el de la emoción social, la búsqueda de una historia explicativa, el segundo de 1932 a 1950, denominado entre dos crisis, Basadre concibe la historia como afirmación de la nacionalidad, investigar los aspectos que dan testimonio de la existencia de la nación peruana, incluyendo los problemas; y el tercer ciclo va de 1950 a 1981, es de la renovación crítica y metodológica, intento de nuevas perspectivas, Mannarelli escribe al respecto que Basadre tuvo "la necesidad de sobrepasar la valoración individual del hecho histórico en busca de una mejor comprensión del mismo en relación con otros acontecimientos que aislados carecen de significado, pero que en conjunto proporcionan un sentido manejable más en términos de un sistema de relaciones dinámicas diferente a la forma estática de la noción de estructura" (Mannarelli, 1982: 100).

Consideramos en este trabajo, una clasificación peruanista de su obra ${ }^{3}$, la cual dividimos en tres grupos: un primero lo componen sus trabajos: La Multitud, la ciudad y el campo (1929), La Iniciación de la República (1929), Perú. Problema y Posibilidad (1931), La Promesa de la vida peruana (1943), incluimos además "Meditaciones sobre el destino histórico del Perú" (1947), estas se caracterizan por las reflexiones sobre la realidad pasada y el futuro del Perú, en este grupo se distinguen ensayos y obras propiamente historiográficas, como son la Iniciación... y 
la Historia del Derecho Peruana (1937), en estas obras, Basadre se proyecta a temas que desarrollará profunda y ampliamente en la Historia de la República del Perú.

El segundo grupo está conformado, exclusivamente por la Historia de la República del Perú. Debemos señalar la presencia de dos subdivisiones: a) una comprende desde la primera edición aparecida en 1939 hasta la cuarta de 1949, esta se caracteriza por la presencia de una historia política-narrativa que el mismo autor reconoce en "conversaciones" que sostuvo con Pablo Macera (Macera, 1979: 39- 40). b) otra desde la quinta edición de 1961 hasta la séptima en 1983; la inclusión de otros aspectos en la vida histórica republicana, son los que las caracterizan. Debemos incluir además en este grupo, su artículo "Notas sobre la experiencia histórica peruana", publicado en 1952 en la Revista Histórica; aquí postula su tesis de la continuidad en el tiempo de la historia del Perú, afirma que "el Perú se hace en su historia, y que lo que presupone esta historia es el Perú" (Basadre, 1952: 6). Este artículo resulta fundamental, para el planteamiento de una teoría del Perú, que podemos complementar con el titulado "Teoría del Perú", publicado en la revista Excélsior en 1935.

Como vemos el peruanismo de Basadre se afirma con elementos surgidos de una reflexión sólida sobre la realidad histórica peruana, lo cual lo aleja de toda consideración de carácter literario o solamente cívico; es lo que podríamos llamar la búsqueda de una afirmación del Perú sobre una base histórica. En este sentido el pensamiento de Basadre, reconociendo antecedentes en la generación del 900, resulta vigoroso y dinámico, como producto de un planteamiento histórico.

Debemos considerar la "Historia de la República del Perú", como el eje de su obra peruanista, la unidad temática de sus investigaciones, y como resultado más complejo y estable de éstas; en cierto modo, convergen, sobre la Historia de la República del Perú, las ideas y ensayos anteriores, a su primera edición en 1939, $y$, se desprenden de esta obra monumental, libros, estudios y trabajos posteriores, que desarrollan temas señalados en ella. Gráficamente, intentamos representar la obra de Basadre, por dos triángulos, unidos por la base, del vértice superior al inferior baja la escala de tiempo, en la unión de ambas figuras se encuentra la Historia de la República del Perú.

El tercer grupo esta constituido por sus trabajos: Elecciones y Centralismo (1980), "El Azar en la Historia"... (1973), "Para un esquema histórico sobre las elecciones peruanas" (1978), "Materiales para otra morada" (1960), las "Bases Documentales" (1971), y las reediciones "Perú. Problema y Posibilidad" (1978) a las que agregó Reconsideraciones 47 años después, La multitud, la ciudad y el Campo... (1980), en estos amplia los temas desarrollados en la historia de la república.

El conjunto de estas obras son peruanistas por dos razones fundamentales: primero, que en la producción historiográfica el tema esencial es el Perú, y segundo, que sus trabajos de historia estudian aspectos ele la vida peruana.

Además resaltamos, como lo hiciera David Sobrevilla, el uso de "peruanismos" y de giros coloquiales en los textos de historiografía de nuestro autor, podríamos decir que Basadre utilizaba un estilo de 
redacción con un lenguaje característicamente lleno de peruanismos (Sobrevilla, 1992).

\subsubsection{Comprender y explicar la historia del Perú}

Estas dos palabras, comprender y explicar, son, en el fondo, el gran objetivo de la investigación histórica. El esfuerzo intelectual del historiador, para recrear el pasado, y de ése modo conocerlo, tiene como propósito encontrar su sentido, también con una finalidad ulterior: comprender el pretérito para explicar el presente.

No se trata así de una labor de ejercicio mental para eruditos, si no del cumplimento de una función social; Pieter Geyl ha dicho -citado por Basadre-que los historiadores son "los guardianes de la memoria colectiva".

Hay pues una relación directa entre el conocimiento del pasado, alcanzado por el historiador a través de su investigación, con los problemas y dificultades de la sociedad presente, en la que vive. Vale decir, que, por trabajar con el pretérito, el historiador no es una persona fuera de su época, por el contrario, como científico, está profundamente comprometido con su momento, con su realidad, a la que aporta los resultados de su trabajo para brindar a su sociedad, no solo información, sino elementos de cohesión grupal y de identificación social. Esto hace que el ser historiador facilite un ejercicio profesional de elevada relevancia, si no que además confiere a su labor una proyección social fundamental.

En la obra de Basadre podemos apreciar una Idea del Perú, y una respuesta a la pregunta: ¿Qué es el Perú?, cuando escribe que "no soló es el territorio, ni el estado, ni la población; es una creación de la historia que surge de la realidad tangible de los siglos en medio de elementos radicalmente heterogéneos"; agrega además que "el ser esencial del Perú está configurado por la voluntad creadora de aquellos habitantes que pudieron alcanzar un destino inconfundible en un escenario geográfico determinado" (Basadre 1966: 16).

Entendió al Perú no soló como un patrimonio histórico y cultural, sino además como un riesgo, una terca apuesta por el sí, como escribió en "Meditaciones sobre el destino histórico del Perú", así podemos encontrar esta posición cuando, en 1925, retorna a Tacna para colaborar con la realización del plebiscito, y vuelve a afirmar al Perú cuando regresa de Europa en 1935.

Esta Idea del Perú se encuentra en su discurso de agradecimiento al recibir orden del Sol en 1979, nos dice, el Perú es un "país dispar, desigual, en formación y ebullición, con tantas cosas espantosas y maravillosas en su seno. País cuyos horizontes culturales, mirándolos en su integridad, parece cada vez más vastos y complejos, gracias al enorme desarrollo de las ciencias humanas. País de choques y mezclas entre razas inconexas y polivalentes a través del tiempo largo, a veces, cegado por ta embriaguez de momentos alegres y confiados aunque, en más de una ocasión, resultó sumido en un agonizar cruento para tener, luego, extraordinaria aptitud para reaccionar. País de demasiadas oportunidades perdidas, de riquezas muchas veces mal gastadas, atolondradamente, de aclamaciones y dicterios, de exaltaciones desaforadas y rápidos olvidos. País dulce y cruel, de cumbres y de abismos. País de Yahuarhuacac, el Inca, que según la 
leyenda, lloró sangre en su impotencia; y de Huiracocha, el Inca, que se irguió sobre el desastre. País de aventureros sedientos de oro y de dominio sobre hombres, tierras y minas $y$, también, país de santos y de fundadores de ciudades. País de cortesanos según los cuales no se podía hablar de virreyes sino con el idioma del himno y el idioma del ruego. País de las altivas y valerosas cartas que suscribieron Vizcardo Guzmán y Sánchez Carrión, separadas por el tiempo y unidas por la más pura inspiración democrática. País donde, a lo largo del tiempo, gamonales altivos o taimados creyeron vencida a la estirpe de los defensores de los indios entre los que hubo mártires como Juan Bustamante y oradores incorruptibles como Joaquín Capelo. País con millones de analfabetos monolingües con grandes figuras culturales y con un riquísimo arte popular. País de tanto desilusionado, pesimista y maldiciente en 1823 y 1824 mientras que, en esos mismos momentos horribles, Hipólito Unánue voceaba su esperanza terca en el fervoroso periódico "Nuevo día del Perú". País donde, en la guerra de la Independencia, se produjo el bochorno de la escaramuza de Macacona y, poco después, la carga luminosa de los Húsares de Junín. País que entre 1879 y 1883 , se enredó y dividió en un faccionalismo bizantino cuyos efectos letales no lograron contrarrestar, en múltiples rincones de la heredad nacional, numerosos héroes famosos o anónimos cuyos nombres debemos exhumar y que lucharon durante cinco largos años, a diferencia de lo ocurrido en la guerra entre Francia y Alemania en 1870 , limitado a unos pocos meses. País que requiere urgentemente la superación del estado empírico y del abismo social; pero, al mismo tiempo, necesita tener siempre presente con lucidez su delicada ubicación

"Manuel Burga en un artículo titulado "la vigencia de Basadre", utiliza la palabra "claves" para definir estas ideas (Burga, 2000) geopolítica en nuestra América" (Macera, 1979:44-45).

Jorge Basadre es peruanista y lo demuestra en su obra, en su trabajo, en su vida; en donde encontramos las aspiraciones verdaderas de un peruano que siente en el alma al Perú, el afirma que "es un peruano más que entiende el sentido de la patria como un conjunto de derechos inalienables y, al mismo tiempo, como un repertorio de deberes a través de una inmensa diversidad de actividades, cada una de las cuales necesita ser compatible con la legítima existencia de todos [...]. La grandeza y vitalidad de un país se basa en la capacidad y en la productividad de su pueblo" (Basadre, 1979,3-9).

Basadre plantea que la historia del Perú es una continuidad en el tiempo, y que para comprender nuestra historia debemos seguir algunas ideas, según las resume Manuel Burga de la siguiente manera ${ }^{4}$ : al el Perú no es inca, ni español, ni mestizo, es una realidad más compleja, b] el Perú es un país de contrastes y contradicciones, c] la historia del Perú en el siglo XIX es una historia de oportunidades perdidas y de posibilidades no aprovechadas, y d) la promesa de la vida peruana es una presencia constante en la historia del Perú.

Basadre conocía perfectamente los vacíos $y$ las deficiencias de la experiencia histórica peruana, sabia de sus limitaciones, errores, defectos; a pesar de ello mantuvo su "apuesta por el sí", que se expresó en una visión esperanzadora y optimista de lo que podía ser el Perú. En las reconsideraciones... a la segunda edición de El Perú Problema y Posibilidad, reiteró que eran los grandes enemigos prójimo de la vida peruana: los Podridos, los Congelados y los incendiarios; agrego 
-admonitivamente: "Que el Perú no se pierda por la obra o la inacción de los peruanos" (Basadre, 1978.4.14,4.15).

El Perú, para Basadre, "existe como una totalidad en el espacio y como una totalidad en el tiempo. Totalidad en el espacio, es decir armoniosa coexistencia de la "loma" y la puna, del cóndor y del alcatraz, de la quinua y el algodón, el "ichu" y el amancay, de la papa y el algarrobo [...]. Totalidad en el tiempo, es decir un largo acontecer histórico donde lo inca vale sólo en la medida en que supervive dentro de la peruanidad, y en tanto y en cuanto sirve a la peruanidad, y en donde lo hispano vale únicamente si es que se ha adaptado o se lia enraizado en la peruanidad ... quien debe guiarnos es el amor al Perú, el cuidado de los intereses del Perú, la defensa de las conveniencias del Perúl (Basadre, 1935: 11 J.

La idea central del peruanismo es lo que llamó en el título de un libro "La promesa de la vida peruana", que definió como "la esperanza de que viviendo libres cumplirían su destino colectivo". Se refería of sentido de independencia y soberanía con que-se emprendió la lucha por la emancipación. Esta esperanza requirió, en el planteamiento de Basadre, de una teoría, que proponía la idea de la construcción del Perú a lo largo del tiempo, a base de los legados prehispánico y colonial.

Esos legados: territorio, población, lengua, religión y cultura se complementaron con el aporte del sentido de autonomía que hizo la época de la independencia, y que evidenció la existencia de una nueva realidad, que era precisamente el Perú. La esperanza, la promesa nada tiene que ver con la "barata retórica electoral", y se concretó dentro de un ideal de superación individual y colectiva. La promesa peruana recogía elementos históricos de la experiencia del pasado, la expectativa de bienestar bajo los incas y que se expresó en los ideales de libertad y unión o democracia en la independencia. La promesa, nos dice Basadre, tiene fuerza formativa e inspiradora, los mejores la recogen y la llevan adelante.

Formula una pregunta esencial: ¿Para qué se fundó la república?, y responde "para cumplir la promesa que en ella se simbolizó"; la promesa, reitera, es un ideal que orienta a los pueblos. Tampoco se trata de una visión romántica del pasado peruano, por el contrario, a partir del análisis histórico realiza, advierte, las "caídas y resurgimientos del Perú", o las oportunidades no aprovechadas y aún más: el olvido de los errores del pasado que conduce a su repetición todo ello dentro de una perspectiva analítica. En la Historia de la República del Perú, cuando se refiere a los factores que nos condujeron a la derrota en la guerra de 1879, y que forman parte de un esquema aplicado en un libro nuestro (Quiroz, 1984).

Ser fieles a esa promesa, ser leales con quienes "hicieron el Perú" es una tarea que asigna a las generaciones del presente, como "deberes de mañana". Sin duda, el esfuerzo de una visión y lectura peruanista de nuestra historia tiene que ver con la necesidad de reflexionar sobre el presente, considerando la experiencia del pasado.

El Perú, dijo Basadre, es un "país dulce y cruel", para señalar contradicciones evidentes en la historia y la vida del país, pero en el fondo de él alienta un ideal, y cada peruano puede "apostar por el sí", que es hacerlo por el Perú.

En la vasta obra historiográfica de Basadre se advierte que el Perú es su unidad 
principal de análisis como totalidad histórica.

Así la historia del Perú es percibido por el gran investigador en una perspectiva de una construcción inacabada en laque alienta una promesa que le dio vida. Hay una estructura histórica del Perú como totalidad, donde sus elementos constructivos provienen del pasado que revela Basadre en sus libros.

Es importante llamar la atención acerca del hecho que los grandes hitos históricos están planteados en la obra de Basadre, sobre todo en la "Historia de la República del Perú", pero alrededor de ella, monumental, encontramos libros de interpretación histórica, artículos y ensayos que demuestran una lectura peruanista, esperanzada y abierta al futuro, además de recoger la experiencia del pasado a la que encuentra un signo positivo en el que el Perú es siempre una expectativa, a pesar de las sombras que existieron al lado de las luces.

Así la lectura peruanista que hemos explorado en la obra historiográfica de Basadre, no es un recurso literario, ni romántico, es resultado de un largo proceso de investigación de toda la vida del historiador, por lo tanto es resultado de un trabajo profesional y paciente de búsqueda de información, crítica y síntesis no cabe duda de la seriedad y del rigor ele la historiografía de nuestro autor, de allí que su peruanismo sea constructivo y sano para los peruanos de hoy.

Las páginas de la obra historiográfica de Basadre, nos ofrecen una lectura peruanista de nuestra historia, objetiva, con sentido ético y con afirmación de valores, sin pasiones ni subjetivismo.
Quienes necesitamos estudiar y conocer al Perú, bien hacemos en acercarnos a la obra historiográfica de Jorge Basadre: alli encontraremos nuestra realidad cómo fue y cómo debemos comprometernos. en hacerla.

\section{REFERENCIAS BIBLIOGRÁFICAS}

Banco Central de Reserva Del Perú; Jorge Basadre. La historia. Su historia, 1982 Departamento de Proyección Cultural, Lima.

Basadre, Jorge; Teoría del Perú. En: "Excelsior". Revista mensual peruana, Año VI, 1935 №100-101, Enero, Lima.

1947 Meditaciones sobre el destino histórico del Perú, Ed. Huascarán, Lima.

1952 Notas sobre la experiencia histórica peruana. En: Revista Histórica. Órgano del Instituto Histórico del Perú, Tomo XIX, Lima.

1960 Materiales para otra morada, Ed. La Universidad, Lima. 1962 Los fundamentos de la Historia de! Derecho, Editorial Universitaria, 2a ed. , Lima.

1965 En torno a la teoría de la 1 listona en: Historia y Cultura, Vol. I, № 1, Lima.

1968 Historia de la República del Perú, Editorial Universitaria, Ga ed. , Lima.

1971 Introducción a las Bases Documentales para la Historia de la República del Perú. Con algunas reflexiones. PLV Editor, Lima.

$1973 \mathrm{El}$ azar en la historia y sus límites, PLV Editor, Lima. 1975 La vida y la historia, Fondo del libro del Banco Industrial del Perú, Lima. 
1978 Para un esqema histórico sobre las elecciones peruanas. Universidad Nacional Mayor de San Marcos, Lima.

1978 Perú: Problema y posibilidad. Ed. Bco. Internacional del Perú. Lima.

Burga, Manuel y Margarita GIESECKE; La Vigencia de Basadre. En: Caretas, 30 de junio, Lima, 2000.

Cayo Córdova, Percy; Historiador por vocación. En: Copé, Vol. XI, № 29, Lima, 2001.

Cayo Córdova, Percy (Compilador); Antología de Jorge Basadre, Fundación Manuel J., 2003, Bustamante de la Fuente, Lima.

Delpar. Helen; Las ideas históricas de Jorge Basadre. En: Revista Chilena de Historia y Geografía, N ${ }^{\circ} 131$, Santiago de Chile, 1963.

Macera Pablo; La historia en el Perú: Ciencia e Ideología En: Amaru, $\mathrm{N}^{\circ} 6$, Abril- junio, Universidad Nacional de Ingenierías, Lima 1968.

Conversaciones con Basadre, Mosca Azul Editores, 2' ed. Lima, 1979.

Perú de Basadre. En: Las Furias y las Penas, Lima, Mosca Azul, Lima 1983.

Palabras de presentación de la obra de Jorge Basadre "Perú Problema y - Posibilidad". 4ca. Edición, 1994.

Mannarelli, María Emma; Jorge Bassadre: su obra y "La República Aristocrática", Tesis Para optar el grado de Bachiller en Letras y Ciencias Humanas, Pontificia Universidad Católica del Perú, Lima, 1982.
Marrou, H. I.; El conocimiento histórico, Biblioteca Universitaria Labor, Barcelona, 1968.

Maticorena, Miguel; La Nación de Jorge Basadre. En: Perú Contemporáneo, $N^{\circ}$ I. Lima,2001.

Miro Quesada, Francisco; Historia y Teoría en la obra de Jorga Basadre. En: Historia. Problema y Promesa. Homenaje a Jorge Basadre, Ed. Pontifica Universidad Católica del Perú, Lima, 1978.

Nugent, José Guillermo; El laberinto de la choledad, Ed. Fundación F. Eberth, Lima, 1992.

Pacheco Vélez, César; Los historiadores del Perú en la Generación del 900. en: Fanal, Vol. XIX, № 69. 1964, Lima.

Jorge Basadre (1903-1980) ó la pasión por la historia. En: Revista de Historia de América, $\mathrm{N}^{\circ} \mathrm{g} 2$, julio- diciembre, México, 1981. El método histórico de las generaciones y la Generación peruana del novecientos. En: Ensayos de Simpatía, Universidad el Pacifico,Lima, 1993.

Quiroz Paz Soldán, Eusebio; Cien años después 1879-1979. Reflexiones sobre la Guerra del Pacífico, Fundación Manuel J. Bustamante de la Fuente, Arequipa, 1984.

El legado de Jorge Basadre, Universidad Jorge Basadre Grohmann, $N^{\circ}$ I, enerojunio, Tacna, 1988.

Jorge Basadre: Maestro y Amigo. En: Acta Herediana, segunda época, Vol. 33, abril- septiembre, Universidad Peruana Cayetano Heredia, Lima, 2003. 
Sobrevilla, David; Prólogo, En: Jorge Basadre, Perú. Problema y Posibilidad y otros ensayos, Ediciones Biblioteca de Ayacucho. Caracas 1992.

Topolsky, Jerzy; Metodología de la historia, Editorial Cátedra, Madrid, 1982.
Universidad de Lima; Primer Encuentro Internacional de Peruanistas, Tomo I, UNESCO- Universidad de Lima- Pondo de Cultura Económica, Lima, 1998.

\section{Correspondencia}

Eusebio Quiroz Paz Soldán Universidad Nacional San Agustín Arequipa
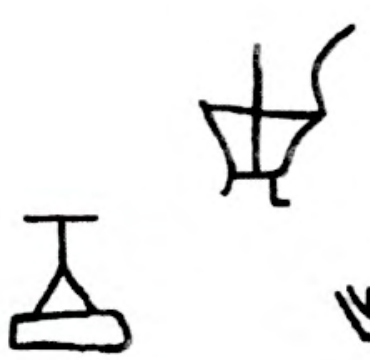